\title{
LUCÍOLA E O TRÁGICO: ESTUDO ACERCA DAS MARCAS DO HERÓI TRÁGICO EM UM PERFIL DE MULHER ALENCARIANO
}

Heitor Victor*

RESUMO: Recorrer aos clássicos para entender nosso tempo não é mesmo nenhuma novidade. Apelar para a tragédia grega a fim de identificar o que persiste em nossa compreensão acerca de nós mesmos se tornou lugar comum de investigações em diversas áreas de interesse. Tal estratégia se repete em razão, evidentemente, de uma inesgotável potência alegórica acerca da existência humana. $\mathrm{O}$ que pretendo neste breve trabalho é uma análise, em linha comparativa, das marcas do trágico na heroína Lúcia de Alencar, personagem que o próprio autor considera um de seus perfis de mulher. Para tal, dialogo com Benjamin, que se apresenta como um elo de compreensão do herói trágico, figura esta que se mostrou mais longeva do que a própria tragédia helênica.

Palavras-Chave: Lucíola; Trágico; Heroína

\section{LUCÍOLA AND THE TRAGIC: ESSAY ABOUT THE MARKS OF THE TRAGIC HERO IN A WOMAN PROFILE OF JOSÉ DE ALENCAR}

ABSTRACT: It is no novelty that a return to the classics helps to understand our own time. It is even a commonplace in many research fields that an approach to greek tragedy makes it possible for us to better understand ourselves. Such a strategy still turns out to be suitable because there is an ongoing possibility of creating allegories of human existence. My aim in this short essay is to perform a comparative analysis of the tragical features of Lúcia, an important character of José de Alencar's prose who the author himself deems to be a crucial example of his depictions of the feminine. In order to do that, I draw upon Walter Benjamin's work, which provides us with a comprehensive overview of the tragic hero - who actually proved himself to be more important than the helenic tragedy itself.

KEYWORDS: Lucíola; Tragic; Heroine.

\section{Introdução}

O teatro trágico dos gregos não pode mais retornar, isso é um fato, mas é marcante a sua presença ainda em nossa literatura ocidental. Analisar o elemento trágico não é necessariamente uma novidade, mas sempre se mostra desafiador relacionarmos o trágico à estrutura de composição da personagem do romance na literatura moderna. O presente trabalho pretende,

\footnotetext{
* Mestrando em Teoria da Literatura e Literatura Comparada pela Universidade do Estado do Rio de Janeiro. E-mail: heitor-victor@ hotmail.com
} 
pois, fazer uma leitura da personagem Lúcia, da obra Lucíola de José de Alencar, pioneira da série perfis de mulher, como construída sob o signo do trágico, uma herança legada pelo teatro grego e que perdura em nossa cultura.

O desafio que salta aos olhos é certamente as dificuldades de se transpor para o romance características da personagem do texto dramático, ou entender nesta a capacidade de se apresentar com a profundidade comum ao romance. É possível entender, contudo, que, retiradas as divergências práticas do meio de veiculação das narrativas, sobram elementos em comum que residem no imaginário coletivo e só fazem enriquecer o repertório de leituras que nos permite a prosa alencariana do século XIX.

Lúcia é uma das heroínas mais complexas de seu autor, capaz de em poucas páginas fazer o leitor se questionar sobre sua verdadeira natureza, ora por sua candura, ora por sua ironia ácida; apego e desprendimento ímpares no cenário romanesco de um tempo que vê transbordar a quantidade de novas e encantadoras personagens. Nossa heroína permite-nos destacá-la exatamente por encerrar um signo que extrapola o estilo de seu tempo, por meio de grandes dicotomias: autoconsciência e culpa, sacrifício e desejo, silêncio e sedução; a personagem se nos mostra única no cenário veloz e dinâmico dos romances de folhetim.

\section{Sublime Decaído, Uma Alegoria}

No intuito de criar um elemento intermediário entre o herói da tragédia e o herói trágico, que mostrarei estar presente no romance Lucíola, de José de Alencar, será preciso recorrer à descrição desse herói feita por Walter Benjamin (2011) acerca do drama trágico alemão. Enquanto aparato cênico ou mesmo de criação literária encontramos outro contexto e outra realidade, mas o elemento fundamental ainda estará lá presente. O herói trágico manterá uma série de aspectos essenciais que o transformam no portador da angústia humana, sem perder o inexorável do mito, despido ainda mais do movimento de ritualização religioso. É o trágico que permanece e esse será fundamental para a construção de uma identidade nacional do drama alemão, segundo o autor, o que nos mostra o potencial desse herói trágico no processo de aproximação entre o discurso formador e o seu espectador (BENJAMIN, 2011).

Um primeiro elemento identificado por Benjamin (2011) que nos interessa no herói trágico é o seu caráter alegórico, se é que posso falar em alegoria do mito que já o é em essência. Certamente, contudo, figura nesse elemento a grande potência reflexiva da personagem trágica que poderá ser transportado para Lúcia. Ao relevarmos a ambição do autor de traçar perfis de mulher ${ }^{1}$, a alegoria destaca Lúcia de Emília e Aurélia, o que faz evidenciar naquela a tragicidade em comparação com estas. Deixe-me verificar antes e em linhas mais gerais o que entende Benjamin por alegoria no drama trágico.

Devo dispensar, em razão de objetivos práticos, a discussão do autor acerca das concepções de alegórico e simbólico para o barroco e para o romantismo para ir diretamente ao ponto, o alegórico é entendido como aquele que supera a unidade da obra e se posiciona com transcendência, à medida que o símbolo se encerra em si mesmo, mostra identidade e um caráter próprio da obra em que se coloca. Benjamin recorre a Goethe para mostrar a concepção romântica de símbolo e alegoria: "Há uma grande diferença entre o poeta procurar o particular para chegar ao geral e contemplar o geral no particular. No primeiro procedimento temos uma alegoria e o particular serve apenas como exemplo, como caso exemplar do geral" (BENJAMIN, 2011, p. 171).

\footnotetext{
${ }^{1}$ Não devemos deixar de reconhecer que essa intenção descritiva, de construção de um perfil, apresenta-se como um elemento romanesco, do narrador de Lucíola. Como visto no primeiro capítulo da obra, quando o narrador se justifica a G. M., sua pretensa correspondente: "É um perfil de mulher apenas esboçado" (ALENCAR, 1972, p. 121). A todo momento que eu tocar nesse ponto se deve reconhecer que a nossa base reside antes de tudo nesse caráter narrativo do romance alencariano.
} 
A despeito da valoração feita por Goethe, seguiremos a leitura de Benjamin para entender Lúcia como o caso particular representativo de um perfil maior, o da mulher que encarna o anjo caído, seu nome dá a grande indicação dessa relação alegórica, mas a mesma não deixa de aparecer ao longo da obra. Reconhecerei em minha análise, na Lúcia de Alencar, a alegoria da mulher sublime que decai, em todo o seu caráter dúbio, mas ainda assim permanente, que morre ao final do romance não à toa, mas de maneira necessária para consolidar a aspiração alegórica desse perfil de mulher, talvez o mais ousado de Alencar. Benjamin reconhece que

o seu (da alegoria) significado é aquele que o alegorista lhe atribuir. Ele investe-o desse significado, e vai ao fundo da coisa para se apropriar dele, não em sentido psicológico, mas ontológico. Nas suas mãos, a coisa transforma-se em algo de diverso, através dela ele fala de algo de diverso e ela torna-se para ele a chave que lhe dá acesso a um saber oculto que ele venera na coisa como seu emblema. É nisso que reside o caráter escritural da alegoria. (BENJAMIN, 2011, p. 196).

Esse será, portanto, o meu ponto de partida. Para não deixar qualquer dúvida sobre essa relação, devo me deter nesse tema ainda para mostrar na obra algumas marcas dessa relação. A começar pelo elemento dramático de narração, o recado de G. M. "ao autor". Após reconhecer a grandeza da personagem e o valor da narrativa que se seguirá, dramaticamente posta como uma publicação da mesma, G. M. afirma: "Não será a imagem verdadeira da mulher que no abismo da perdição conserva a pureza d'alma?" (ALENCAR, 1972, p. 120). Não se pode desaperceber que é usado não a referência definida, dedicada à Lúcia, mas uma referência geral a todas as mulheres. É exatamente nesse caráter genérico que residiria o valor alegórico de que trato neste trabalho.

Podemos também recorrer aos eventos narrados no interior do romance para vermos personificada a alegoria do anjo caído, seja pela capacidade de transitar com primor entre um e outro, digo, entre o angelical e o demoníaco, ou seja, por encerrar em si mesma os dois extremos. Lúcia se nos apresenta apenas pela narrativa de Paulo, não se pode esquecer, e muito de sua transitoriedade pode residir apenas nas impressões desse narrador personagem, mas isso em nada muda o seu caráter alegórico. Um episódio que expressa com clareza a ambivalência de Lúcia é o de seu primeiro encontro íntimo com Paulo. Em curto espaço de tempo, cronológico e narrativo, vemos uma transformação que beira a ida pronta do sagrado ao profano. No momento em que avança sobre Lúcia, Paulo reconhece:

\footnotetext{
Quando porém os meus lábios se colaram na tez de cetim e meu peito estreitou as formas encantadoras que debuxavam a seda, pareceu-me que o sangue lhe refluía ao coração. As palpitações eram bruscas e precipites. Estava lívida e mais branca do que o alvo colarinho do seu roupão. Duas lágrimas em fio, duas lágrimas longas e sentidas, como dizem que chora a corça expirando, pareciam cristalizadas sobre a face, de tão lentas que rolavam. (ALENCAR, 1972, p. 134-135).
}

Vemos aqui com a reação genuína de Lúcia, somada às lágrimas, sua comparação ao choro da corça, notamos aqui o temperamento puro que nos surpreende a todos, narrador e leitor. Surpresa que se justifica com a mudança abrupta de Lúcia para entregar a imagem que nos foi construída pelos pares de Paulo, de que nossa heroína se tratava de uma cortesã das mais hábeis.

Era outra mulher. $\mathrm{O}$ rosto cândido e diáfano, que tanto me impressionou à doce claridade da lua, se transformara completamente: tinha agora uns toques ardentes e um fulgor estranho que o iluminava. Os lábios finos e delicados pareciam túmidos dos desejos que incubavam. Havia um abismo de sensualidade nas asas transparentes da 
narina que tremiam com o anélito do respiro curto e sibilante, e também nos fogos surdos que incendiavam a pupila negra. (ALENCAR, 1972, p. 136).

Nessa transformação se apresenta a indistinguível transição do sagrado do choro da corça para a respiração sibilante, demoníaca em lascívia. Seria inútil continuar enumerando os momentos em que se evidencia tal transformação, acredito que esses episódios partem da anteriormente citada alegoria que pode nortear nossa leitura do romance.

Não nos será nunca possível bater o martelo sobre tal questão, seria Lúcia o símbolo de Goethe ou a alegoria de Benjamin? Somando, contudo, as marcas supracitadas a ainda o reconhecimento de outras marcas do trágico, preferirei me manter na leitura de Benjamin, de que o alegórico é ainda desejável, mesmo no romance, exatamente por seu valor transcendente e, assim, poderemos entender Lúcia e seu perfil exclusivo de mulher como também dotado de valor reflexivo e generalista das angústias femininas.

\section{Marcas do Herói Trágico}

As lágrimas do episódio transcrito acima servem como indicador do demais elementos de proximidade entre o herói trágico de Benjamin e a Lúcia de Alencar. Tal choro evidencia uma dor suprimida, mas acima de tudo encerra em si quatro aspectos sobre os quais tratarei neste trabalho: o silêncio, a culpa, a consciência e o sacrifício. O silêncio de quem guarda para si o seu verdadeiro eu, suas dores e reflexões. É nas lágrimas que temos o primeiro vislumbre da profundidade trágica de Lúcia. A personagem demonstra nesse exato momento plena consciência de si, de seu destino, e sente a culpa que pesa sobre si, as lágrimas expressam o ardor do seu sacrifício, pois são sublimadas por sua candura. Vejamos adiante o que pretendo dizer com esses quatro aspectos e sua relação com o trágico.

Devo principiar, contrariando a ordem anterior, pelo sacrifício, para manter a abordagem de Benjamin. $\mathrm{O}$ autor entende que o herói trágico realiza sua atuação maior em sua própria morte, o sacrifício maior, e que é exatamente então que o herói se distingue dos demais indivíduos. Benjamin afirma:

A marca identificativa da tragédia não está, pois, num conflito de níveis entre o herói e mundo circundante, [...] mas sim a forma única, grega, de tais conflitos. E onde deve ser procurada essa forma? Que tendência se esconde no fenômeno trágico? Por que causa morre o herói? A poesia trágica assenta na ideia do sacrifício. (BENJAMIN, 2011, p. 108).

Lúcia se sacrifica não apenas porque morre, mas se encerra em sua morte uma entrega definitiva, a Paulo e à sua irmã Ana. A morte de Lúcia é decisiva para a construção e para a profundidade da personagem, além de ser elemento fundamental para a generalidade constitutiva da alegoria. Ainda mais que o sacrifício do herói trágico não é um sacrifício comum. Seguindo ainda o raciocínio de Benjamin temos:

o sacrifício trágico difere, no seu objeto - o herói - de todos os outros, e é ao mesmo tempo inaugural e terminal. Terminal no sentido do sacrifício expiatório devido aos deuses, guardiães de um antigo direito; e inaugural no sentido de uma ação que, em algum lugar desse direito, anuncia novos conteúdos da vida do povo. (BENJAMIN, 2011, p. 108).

Ou seja, o sacrifício de Lúcia é terminal, expiatório de sua vida de perfídia. Lúcia reconhece em seus últimos momentos para Paulo a sua importância e exatamente por isso por ele se sacrifica 
- Paulo! Paulo... Tu bem sabes que com essa palavra me farias cometer crimes, se crimes fosse necessário para te provar que eu só vivo da vida que me dás, e me podes tirar com um sopro. Não sou eu criatura tua, não renasci pela luz que derramaste em minha alma! Não és meu senhor, meu artista, meu pai e meu criador? (ALENCAR, 1972, p. 243).

O sacrifício de Lúcia, como se evidencia, não está apenas na morte, mas na sua entrega completa. Entrega que se apresenta como sua única forma de se redimir da vida que levara. $\mathrm{O}$ sacrifício, reconhecendo ainda tais aspectos de Benjamin, é também inaugural quando se direciona a Ana, sua irmã, em quem enxerga a única continuidade possível. Seja para sua protegida ou mesmo para a continuidade da vida de Paulo, possível apenas com o encerramento da sua própria vida.

Outro aspecto do herói trágico de Benjamin presente em Lucíola é o silêncio, já mencionado anteriormente: "O herói trágico tem apenas uma linguagem que plenamente lhe corresponde: precisamente a do silêncio. Assim é desde o início" (BENJAMIN, 2011, p. 109). Esse silêncio é identificável em diversos momentos em Lúcia, pois evoca a resiliência da heroína com o seu fardo. Não é um silêncio de conformismo, ou mesmo qualquer espécie de não se importar que a toma, mas "o testemunho de um sofrimento mudo" (BENJAMIN, 2011, p. 109). É com esse silêncio que Lúcia arrebata o leitor para o seu drama pessoal, não como um perseguidor ou inquisidor, mas como partícipe de seu pesar, de sua dor. Tal silêncio aparece nos momentos de prazer, como quando se divertia no banquete noturno na casa de Sá: "Lúcia fizera uma pausa na sua estrepitosa alegria e caíra no costumado abatimento e distração. Eu a contemplava admirado do letargo que a tornava inteiramente estranha ao que ali se passava, quando ela voltou-se para mim com o seu sorriso de anjo decaído" (ALENCAR, 1972, p. 152153). Ou mesmo em sua face mais sincera, já como Maria: “Quando cheguei, Lúcia estava só no jardim, debaixo de uma espessa e sombria latada de maracujás, tão absorvida em sua meditação que não me percebeu" (ALENCAR, 1972, p. 245).

Seguindo com minha análise comparativa, devo abordar o aspecto da consciência, fundamental para a diferenciação entre uma outra personagem qualquer e o herói trágico. Esse aspecto em especial é importante para a leitura que apresento, por se tratar de algo que claramente distingue o herói romântico convencional daquele que é regido pelo signo do trágico. O herói do romance desconhece completamente o seu destino e reside precisamente nisso suas dúvidas e questionamentos. Nossa heroína trágica, contudo, ainda que também romântica - não o desejamos negar em nenhum momento, se mostra consciente do seu caminho. Para esclarecer esse sentido de consciência, Benjamin traz uma fala de Lukács acerca do reconhecimento da própria morte:

Também a escolha da morte pelo homem trágico... é um heroísmo só aparentemente heroico, só assim visto de um ponto de vista humano e psicológico; os heróis moribundos da tragédia - escrevia há pouco tempo um jovem autor trágico - estão mortos muito tempo antes de morrerem. (BENJAMIN, 2011, p. 117).

Apenas a cargo de exemplificação, que se encaixa bem na ideia de reconhecimento da morte como marca do herói trágico, podemos citar a consciência apresentada por Lúcia antes de sua própria morte: “- Se eu pudesse viver, haveria forças que me separassem de ti? Haverá sacrifício que eu não fizesse para comprar mais alguns dias da minha felicidade? Mas Deus não quis. Sinto que a vida me foge" (ALENCAR, 1972, p. 248).

Devo tratar, por fim, do quarto aspecto a que me reservei neste trabalho que é o da culpa. Sem dúvidas o eixo central de todo o romance de Alencar. A culpa não pode ser entendida, contudo, como o arrependimento de seus atos, ou mesmo sujeição completa ao próprio erro. A culpa como elemento trágico traz um valor de compreensão. Nossa heroína trágica não apenas se lamenta da vida que fora levada a ter, mas por meio da culpa ela se reconstrói, é precisamente 
por meio da culpa que, no fim, em meio ao embate entre anjo e demônio, prevalece sua face angelical e a alegoria alcança a sua plenitude. Recorro ainda às palavras de Benjamin para clarificar essa noção de culpa no drama trágico:

\begin{abstract}
No decorrer da ação trágica, um herói assume e internaliza essa culpa, que, segundo as antigas normas, é imposta aos homens a partir de fora pela desgraça. Ao refleti-la na sua consciência de si, ele furta-se à sua tutela demoníaca. [...] Paradoxal como todas as manifestações da culpa trágica, ela consiste apenas numa orgulhosa consciência de culpa na qual a figura heroica se liberta da servidão que, na sua 'inocência', a sujeita à culpa demoníaca. (BENJAMIN, 2011, p. 135).
\end{abstract}

Essa culpa talvez seja, dentre os aspectos até aqui elencados, o que mais se mostra claro ao longo de Lucíola. Nos momentos de maior comoção, compartilhamos com Lúcia esse seu e genuíno sentimento e é precisamente graças a ele que o lado sagrado desse anjo caído prevalece e nos faz criar a empatia entre leitor e personagem. Vejamos, portanto, dois casos que expressam os dois extremos da culpa vivida por Lúcia. Ora tal sentimento se expressa pela ironia, como quando Paulo, no evento da casa de Sá, tenta singularizar a sua presença e nossa heroína rebate com acidez:

\begin{abstract}
- Ora! Há tanta mulher bonita! Qualquer destas vale mais do que eu, acredite! Demais, quando tiver bebido alguns copos de clicot e sentir-se eletrizado, saberá o senhor de quem são os lábios que toca? Qual? É uma mulher! Uma presa em que ceva o apetite! Que importa o nome? Sabe porventura o nome das aves e dos animais que lhe prepararam esta ceia? Conhece-os?... Nem por isso as iguarias lhe parecem menos saborosas. (ALENCAR, 1972, p. 153).
\end{abstract}

Em outro momento, contudo, vemos a culpa sob outra roupagem, da maneira mais sincera em um de seus momentos de maior entrega:

\footnotetext{
- Tu podes me fazer voltar à treva de que me arrancaste; podes estancar as fontes de minha existência que manam de tua alma; e não me hás de ouvir uma só queixa. A dor, como a alegria, serão sempre benditas, por que virão de ti. Mas, Paulo, a súplica do humilde não ofende. Deus a permite e exalça. Não me retires a graça e a bênção que me deste! Salva-me, Paulo! Salva-me a ti. Salva-me de mim mesma!... (ALENCAR, 1972, p. 243).
}

Não à toa seleciono esta última fala de Lúcia para encerrar a argumentação, pois precisamente aqui a culpa se mostra como o elemento libertador e é aqui que Lúcia talvez tenha entendido e absorvido o orgulho citado por Benjamin para livrá-la da tutela demoníaca. Libertase finalmente da servidão que a acomete por toda a obra. A projeção em Paulo é, certamente, a projeção em um amor libertador, que foi capaz de transfigurar a modalidade da culpa que sentia. É então que Lúcia deixa claro que compreende que a dor e a alegria se complementam e, assim, encerra o perfil da mulher que decaiu, mas que, no fim, projeta em sua alegoria a clareza do seu papel em sua própria narrativa. Essa compreensão faz de Lúcia, a heroína de Alencar que mais beira a perdição, a mais altiva e capaz de se assemelhar à heroína da tragédia e, assim como lá, melhor do que se realmente apresentam homens e mulheres.

\title{
Conclusão
}

Ao recorrer, portanto, às estratégias de identificação da interioridade e de posições constitutivas do herói trágico, acredito que se torna possível clarificar como o teatro grego passou a atuar sobre o mito, por meio de maior variabilidade narrativa do mesmo. Essa possibilidade de apresentar uma personagem mais profunda, ainda que por meio da ação 
dramática, eleva o texto teatral e especificamente a tragédia - que usa a personagem mítica como forma de apresentar seres mais elevados do que os indivíduos da sociedade - ao papel de ressignificar o mito. É por meio dessas personagens dramáticas que a fabulação estática do mito pode apresentar novos argumentos para o meio em que está inserida.

Reconhecendo nas estratégias de interpretação da personagem dramática a ferramenta de atualização do mito, despida do elemento religioso, foi possível analisar com certo grau de convicção o herói da tragédia. Evidenciou-se, como isso, o papel desse herói e sua capacidade de conduzir efetivamente a narrativa mítica para novos caminhos interpretativos, possibilitando essa narrativa a se apresentar sob nova perspectiva. O herói, visto dessa maneira, ganha destaque como formador de questionamentos e permite ao leitor/espectador, por meio do elemento trágico, estabelecer nova compreensão.

Esse herói trágico permanece com o seu poder reflexivo mesmo fora do contexto mítico, levando-nos ao reconhecimento do trágico como formador efetivo de questionamentos. São estes aspectos trágicos, que Benjamin identifica como herdeiros do teatro grego no teatro alemão, que eu resgato como possíveis na construção de profundidade do herói do romance, é precisamente sob esses aspectos que Lúcia - a heroína romântica, mas dotada do elemento trágico - é capaz de saltar aos olhos do leitor como dona de seu próprio destino, jamais apenas sujeita ao mesmo. Com isso cada traço da heroína de Alencar é capaz de se mostrar não apenas como marca de um perfil de mulher, mas também o perfil de um aspecto comum a todas as mulheres. Somente por meio da alegoria do anjo caído se poderia alcançar tamanha projeção dentro de um cenário em que o indivíduo é professado como ponto central da construção de uma obra de arte.

\section{REFERÊNCIAS}

ALENCAR, José de. Obras Imortais da Nossa Literatura: José de Alencar: IracemaLucíola. São Paulo: Editora Três, 1972.

ARISTÓTELES. Poética. In A Poética Clássica. São Paulo: Cultrix, 12ª edição, 2005.

BENJAMIN, Walter. Origem do Drama Trágico Alemão. Belo Horizonte: Autêntica Editora, 2011.

CANDIDO, Antonio. A Personagem do Romance. In A Personagem de Ficção, São Paulo: Perspectiva, $13^{\text {a }}$ Edição, 2014.

ELIADE, Mircea. Mito e Realidade. São Paulo: Editora Perspectiva, 2ª edição, 1986.

PRADO, Décio de Almeida. A Personagem no Teatro. In A Personagem de Ficção, São Paulo: Perspectiva, 13 ${ }^{\mathrm{a}}$ Edição, 2014. 